\title{
A Constructional Approach to V-R Constructions
}

\author{
HU Meng-ying \\ Hunan University, Changsha, China
}

\begin{abstract}
This paper will explore the V-R (verb-result) constructions from the constructional approach. In the book Constructions: A Construction Grammar Approach to Argument Structure (1995), Goldberg recognized the importance of constructional meaning in argument realization and proposes the fusion of verb and construction in that both of them contribute to the linguistic expression. Agreeing with this proposal, the author further suggests a more integrated view of the components and the construction. The author believes a grammatical expression requires the compatibility of the components and the whole construction. Considering the symbolic structure has the semantic structure and phonological structure as its two poles (Langacker, 2008), the author will elucidate the semantic structure in this thesis. Moreover, the semantic structure will also include the pragmatic and discourse meaning (Croft, 2001; Croft \& Cruse, 2004), hence, the context is essential to the interpretation and acceptability of linguistic expressions.
\end{abstract}

Keywords: constructional approach, V-R (verb-result) constructions, integrated, cross-linguistic variations

\section{Introduction}

Goldberg's (1995) work in proposing that language can be generalized in constructions and attaching importance to the semantic properties of constructions in argument realization is influential and illuminative. The generative paradigm proposed by Chomsky (1981) ignores the constructional meanings and explains the syntactic patterns in terms of general rules or principles. However, the supposed rules do not always apply for the syntactic patterns and the generativists attribute the idiosyncratic properties to individual lexical items. Also, there is an arising projectionist view of syntactic-semantic interface which suggests verb's lexical semantic representation determines the morpho-syntactic realization of its arguments. Such an approach that in effect inherits the idea from generativism and takes the verb as the determinant factor is not free from criticism. As Rice (1988, p. 211) pointed out, a verb's meaning and subsequent syntactic behavior is not atomistic and that the meaning and usage of the verb is embedded in the context in which it appears. This insight is in accordance with the spirit of radical construction grammar (Croft, 2001). The constructional approach by Goldberg (1995, p. 1) also explicated that there are aspects which must be recognized as constructions independent of the lexical items that instantiate them. She also proposed an integration of verb and constructions. This paper is constructed based on Goldberg's argument and further suggests a more explicit and integrated view of the components and the construction. The format of this paper is as follows. Section "Verb and Construction" briefly introduces the projectionist view (e.g., Rappaport Hovav \& Levin, 1998) and turns to the constructional approach. Section “A

HU Meng-ying, master, School of Foreign Language, Hunan University. 
Critical Review of Construction Grammar Approach” gives a critical review of Goldberg's Construction Grammar Approach. Section “A More Integrated Constructional Analysis of V-R Constructions” develops a more integrated constructional view and applies it to the V-R (verb-result) constructions in both Chinese and English ${ }^{1}$. Section “Cross-Linguistic Variations and Explanation” presents typological evidence to the constructional approach which the author believes gives a better explanation of the linguistic variations.

\section{Verb and Construction}

There are two different views about the relationship between verb and the construction. In the projectionist approach (Rappaport Hovav \& Levin, 1998), the verb itself boasts of semantic representation which determines the realization of its arguments and hence the construction is neglected. The semantic representation consists of two components: a lexical semantic template and a "root". The lexical semantic template structures a set of verbs in the same category and the "root" is the idiosyncratic part which distinguishes the verb from other verbs. For instance (Levin, 2004, p. 1) (see Example 1):

Example (1) Dry: [[x ACT] CAUSE [BECOME [y $<$ DRY > ]]]

When dry is used as a verb, it belongs to the class of change of state and the template is [[x ACT] CAUSE [BECOME [y < STATE > ]]]. It is the "root" that distinguishes itself from other verbs in the same category. This bottom-up approach also makes a distinction between result and manner verbs (Rappaport Hovav \& Levin, 2010, 2011, 2012). According to the distributions of different verbs in English, Levin and Rappaport Hovav (1995) proposed result verbs have the property that the patient must be realized and can only be realized as a direct object while manner verbs have no such constrained argument realization options. This proposal actually reminds us of the DOR (direct object restriction) which specifies that result X-phrases will be predicated of the noun phrases in object position in English (Simpson, 1983; Rappaport Hovav \& Levin, 1995). Thus, the result verbs like break or kill and the resultative constructions must have the patient as the direct object. However, neither of the generalizations is tenable. In Lemmens' (2006) detailed analysis, we can find that there are exceptions to the suggested proposals (see Examples 2-3).

Example (2) Dawn had begun to break (p. 22).

Example (3) break free, break loose... (p. 24)

As we can see, the result verbs like break can be used in objectless patterns and the resultative constructions like break free also allow bare NPs. In fact, Rappaport Hovav and Levin (1999, p. 210; 2001, p. 774) themselves also recognized there are bare resultatives which DOR fails to explain. The projectionist approach in effect shares the same weakness with the generativism. In the formalist approach, the semantic representation of the verb is called sub-categorization. The commonality of them is that both regard the verb as the decisive factor in argument realization. But the proposed generalizations cannot always account for the linguistic phenomena and there are aspects that the verb itself is hard to explain. And Rice (1988, p. 211) made sense that taking seriously the information which needs to be in the lexicon would lead to an enormous proliferation of lexical entries. The constructional approach seems to be more reasonable in dealing with the relationship between verb and the construction. Inspired by frame semantics, Goldberg (1995) suggested that

\footnotetext{
${ }^{1}$ The V-R constructions are also called resultatives in which V refers to the verb and $\mathrm{R}$ designates the result.
} 
the semantics of a construction defines a semantic frame and proposes an interaction between verb and the construction that the verb meaning should be compatible with the constructional meaning. In the next section, $\mathrm{t}$ will elaborate on the constructional approach.

\section{A Critical Review of Construction Grammar Approach}

In Construction Grammar Approach, Goldberg (1995, p. 43) proposed that verbs are associated with frame-specific roles which are called participant roles, while the constructions are associated with more general roles which are called argument roles. For example, the argument roles associated with the ditransitive construction are agent, recipient, and patient. And for the fusion of the verb and the construction, the most typical case is that the participant roles associated with the verb are in one-to-one correspondence with the argument roles associated with the construction (Goldberg, 1995, p. 51). Take a composite fused structure like the ditransitive and the verb hand for instance:

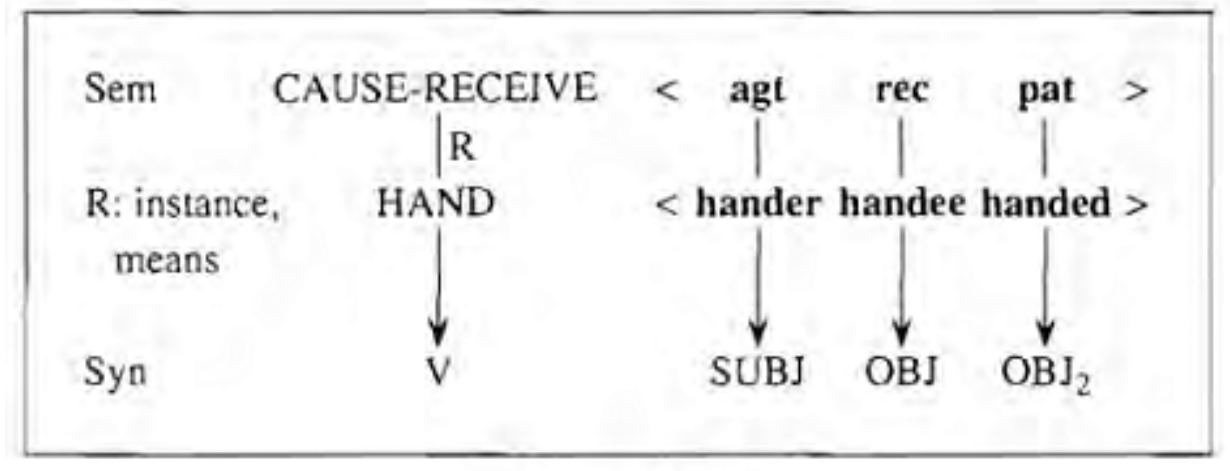

Figure 1. Composite fused structure: ditransitive + hand.

As shown in the Figure 1, the participant roles associated with hand are just more specific than the general roles associated with ditansitive, hence the construction in this case is just a template which sanctions the use of the verb hand. However, in many cases, the participant roles mismatch the argument roles and the construction may add or reduce the role associated with the verb. For example, sneeze is generally regarded as intransitive and has only a profiled participant role but it can integrate with the caused-motion construction. In the expression he sneezed the napkin off the table, the fusion of verb and the construction can be diagrammed as in Figure 2:

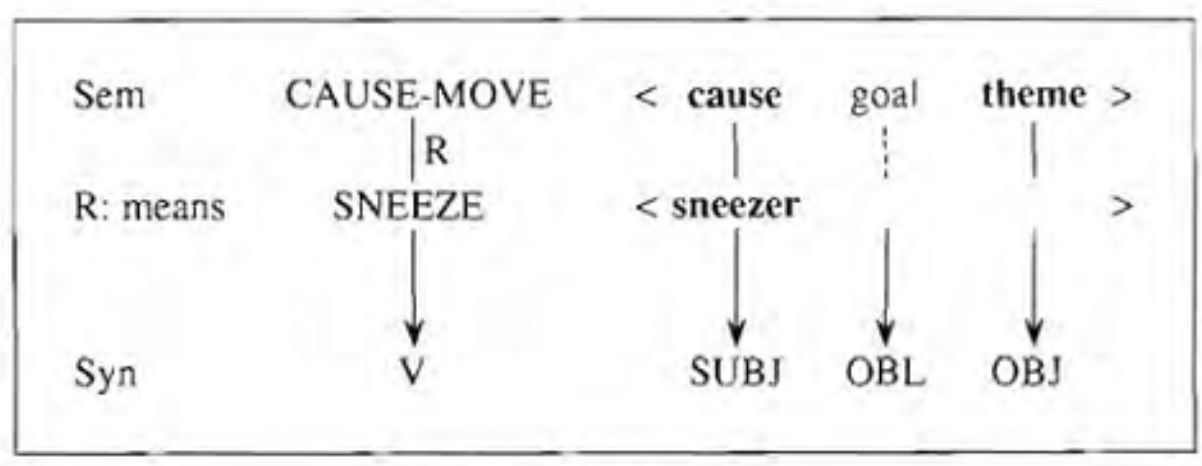

Figure 2. Composite structure: caused-motion + sneeze. 
Hence, the caused-motion construction sanctions the intransitive verb sneeze and assigns the theme on the verb. This constructional approachs thus account for the transitive use of intransitive verbs in the caused-motion construction. However, although Goldberg (1995) proposed the fusion of verb and construction, she made a split of the lexical meaning and the constructional meaning. Langacker (2005, p. 170) argued whether the verb can be said to have a particular meaning is an empirical issue and suggested the preference for monosemy might have been pushed too far. He also believed there is no inappropriate lack of parsimony since the same subschema will characterize both the verb and the construction (Langacker, 2005, p. 171). Enlightened by the usage-based perspective of Cognitive Grammar, ZHANG (2006) pointed out the integration of the verb and the construction proposed by Goldberg is lack of explicit illustration and made use of categorization to account for the regular meaning and extended meaning of the verb. He suggested the unconventional meaning like the causative meaning of sneeze in the caused-motion construction can be simultaneously categorized by the conventional counterparts as well as the constructional schemas. In this fashion, the interaction between the verb and the construction can be explicitly illustrated by means of categorization. The author agrees with this criticism and rejects the invariant meaning of verbs. Moreover, the author believes the categorizing relationship between the conventional meaning and the extended meaning of the verb explicitly shows how the verb can be integrated with the construction when the participant roles do not correspond to the argument roles. In other words, the attack on the Construction Grammar Approach is not to despise the fusion of verb and construction, rather give a more integrated view of verb and construction and explicitly show how the fusion happens. In effect, the author finds this more integrated view of verb and construction will be more constructive and further suggest a well-formed expression needs compatibility among the components as well as the components and the construction.

\section{A More Integrated Constructional Analysis of V-R Constructions}

In this section, the author will propose a more integrated constructional approach and applies it to the analysis of V-R constructions in both English and Chinese. In the author's view, the relationship between the components and the whole construction can be regarded as the relationship between the parts and the whole. The whole is a system. To be a whole, the parts have to work together in a special way. Thus, the function of the whole is dependent on the function of the parts, and in return, the parts can play its role only in the construction. Just like a bicycle, if the equipment is separated from each other, the whole will not work; and, if separated from the whole, the equipment itself will also not work. The relationship between the components and the whole construction can be understood in the similar way to the relationship between the parts and the whole.

\section{Verb and Construction}

The author will first deal with the relationship between verb and the construction in V-R constructions. Take Xiaofang kuhong le yanjing for instance (see Example 4).

Example (4) Mandarin:

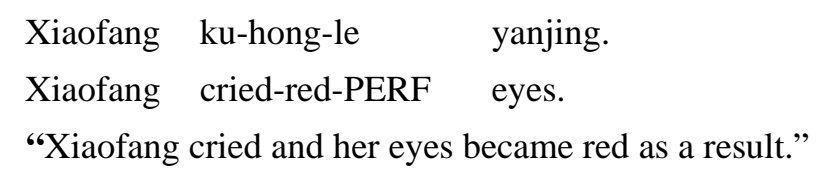

In Chinese, the verb $k u$ is generally intransitive. At first sight, it may seem strange that the intransitive verb can be used in the causative construction in which there's an object behind the V-R compound. So what licenses 
$k u$ with this construction? In the author's opinion, just like the fusion of sneeze and the caused-motion construction, this expression is contributed to both by the verb and the construction. On the one hand, the causative constructional meaning induces the transitive use of the conventional intransitive verb. On the other hand, the rich semantic meaning of the verb provides the basis for the extended meaning in that the act of crying can lead to eyes becoming red. Hence, it is not the case that the unconventional use is contributed to by either the verb or the construction, rather that the combination of them constitutes the construction-congruent meaning. There is one point that needs to be paid attention to. The construction-congruent meaning also relies on the close relationship between the verb and the result in that the fact that crying can make eyes become red ensures the acceptability and grammaticality of this expression. In English V-R constructions, the relation between the verb and the result phrase is also matter of significance.

\section{The Relation Between Verb and Result}

The grammaticality of the V-R constructions is concerned with the relation between verb and the result. Goldberg (1995, p. 84) suggested that the resultatives can not be used to imply an intended or potential change of state, which is used to account for the ungrammatical instances (see Examples 5-6):

Example (5) She allowed it green.

Example (6) She locked him dead.

However, the author thinks the ungrammaticality of the instances can be explained in the perspective of the relationship between the act and the result and that the closeness degree will affect the acceptability. Compare Examples 7-8:

Example (7) She broke the vase into pieces.

Example (8) She touched the vase into pieces.

As we can see, the verb break inherently has an intimate relationship with the result into pieces. In contrast, the act of touching will be hardly construed as the cause that brings about the result. Likewise, the act of allowance and the result of becoming green are not closely related, nor the act of locking him will necessarily make him die. Therefore, while Example 7 is well acceptable, Examples 5, 6, and 8 are not acceptable. In short, the relation between the verb and the result will affect the grammaticality and acceptability of the expressions.

\section{Arguments and the Verb-Compound}

The well-formed expression not only requires the compatibility of the verb and result in the V-R constructions, but also the compatibility of arguments and the verb-compound. Examples 9-10 are from Chinese.

Example (9) Jiankude gongzuo bing-dao-le Lisi.

Tough work sick-fall-asp Lisi.

"Tough work brought Lisi down with sickness."

Example (10) Jiankude gongzuo lei-dao-le Lisi.

Tough work tired-fall-asp Lisi.

"Tough work brought Lisi down with tiredness."

In the author's view, the effect that tough work produces on Lisi is relevant with the grammaticality of the expressions. Although Lisi may feel very tired because of hard working, yet he will not necessarily get sick due to tough work. In other words, tough work will not easily be construed as a cause that leads to someone's sickness. 
Rather, if we are intended to show this causality, we have to use a causality marker which will explicitly show the causation between tough work and Lisi (see Example 11):

$$
\begin{aligned}
& \text { Example (11) Jiankude gongzuo shi Lisi bing-dao-le. } \\
& \text { Tough work make Lisi sick-fall-asp. } \\
& \text { "Tough work brought Lisi down with sickness.” }
\end{aligned}
$$

Hence, while the causation can be implied from our conventional knowledge in Example 10 or explicitly shown by means of the causative marker in Example 11, the arguments and verb-compound in Example 9 are not that compatible in that tough work will not necessarily cause Lisi to fall sick. As a result, Examples 10-11 are more grammatical and acceptable than Example 9.

\section{Arguments and the Construction}

The grammaticality of V-R constructions also requires semantic compatibility between arguments and the whole construction. Goldberg (1995, p. 193) found the resultative constructions with the instrument as the subject are unacceptable and proposes animate instigator constraint. In effect, in the prototypical causative V-R constructions, the subject is an animate agent who has the ability and intention to force on the patient. As a result, the prototypical subject in V-R constructions should be animate and energetic. And when the instrument is used as the subject of the $\mathrm{V}-\mathrm{R}$ constructions, it tends to be considered as unacceptable. Compare the contrast in English (see Examples 12-13):

Example (12) I pounded the metal flat (with the hammer).

Example (13) The hammer pounded the metal flat.

As shown in Examples 12-13, the V-R constructions exhibit animate constraint and rule out the expression when the instrument acts as the subject. Similarly, Mandarin also shows constraint when the subject is not an animate agent (see Examples 14-15):

$$
\begin{gathered}
\text { Example (14) Wo da-kai-le men. } \\
\text { I hit-open-asp door. } \\
\text { "I opened the door." } \\
\text { Example (15) Yaoshi da-kai-le men. } \\
\text { Key hit-open-asp door. }
\end{gathered}
$$

"The key opened the door."

The verb $d a$ originally means hit or beat; here it has no specific content or meaning through grammaticalization. The two instances are illustrated to show that in Chinese, the expression of V-R constructions is also constrained when the subject is not animate.

In short, a well-formed expression needs the compatibility among the components as well as the components and the construction. For the prototypical V-R constructions, the prototype of the subject is an animate agent. And in the causative constructions, the subject should be able to produce an effect designated by the verb-compound on the object. Moreover, in the verb-compound, the act should also be closely related with the result in the way that there is great probability that the act will lead to the designated result. The author considers these findings are significant for the research on V-R constructions. In the next section, the author will further the more integrated constructional approach to explain the cross-linguistic variations in V-R constructions. 


\section{Cross-Linguistic Variations and Explanation}

In attack on compounding parameter (Snyder, 2001) and principle R (Beck \& Snyder, 2001), Son and Peter (2008) proposed a micro-parametric approach to DMMC (directed manner of motion constructions) and resultatives. The compounding parameter and principle $\mathrm{R}$ suggest that a language either allows DMMC and resultatives or disallows DMMC and resultatives. However, in the typological analysis of DMMC and resultatives, Son and Peter (2008) found out that languages with no resultatives may allow DMMC, and vice versa. And based on the micro-parametric approach, they argued that directed motion and resultatives can be further divided into smaller subclasses. Let us first turn to their elaborate analysis of resultatives.

In the research, they observed that there are at least three different situations for resultatives (Son \& Peter, 2008, p. 394). First, the most restrictive one like Spanish can form resultatives only when the verb is like the functional verb make. Then, a less restrictive type such as Japanese allows resultatives when the verb implies some change. Finally the least restrictive type, in which resultative constructions can be formed even with verbs that do not by themselves imply any change of state (e.g., English). The observation of the last two types is also in accordance with Washio’s (1997) findings. As Washio (1997, p. 42) pointed out, while English permits strong resultatives, Japanese does not, though weak resultatives exist in both languages. Therefore, according to the research by Washio, English also belongs to the least restrictive while Japanese belongs to the less restrictive type. Although Son and Peter (2008) outlined a solution that the cross-linguistic variations can be confined to the lexical content of lexical items, yet they did not explain why it is so. In the author's view, the motivations of the subclasses can be explained from the more integrated constructional approach. In the V-R constructions, the act designated by the verb should have an intimate relationship with the result that the practice of the act will necessarily lead to the result. When the verb is instantiated by the schematic causative verb like make, there will be no rigid restriction to $\mathrm{R}$ which only specifies the intended result; hence even the most restrictive languages like Spanish allow the resultative construction when the verb is a functional verb. For the less restrictive, the verb should at least imply some change otherwise the close relationship between the act and the result will not be guaranteed. Thus the less restrictive languages such as Japanese reject the strong resultatives in which the verbs do not by themselves imply any change of state. And finally in the least restrictive languages like English and Chinese, there is the greatest freedom that they allow both weak and strong resultatives.

The integrated constructional approach takes a top-down approach and is more persuasive than the bottom-up approach by Son and Peter (2008). First, the bottom-up approach which suggests variations are bounded by the specification of the lexical items doesn't explain why we should have to class the lexical items into smaller classes and what the motivation of the classification is. In fact, the divisions of different classes are motivated by the relation between lexical meaning and constructional meaning. On the whole, the V-R construction designates that the act will bring about the result; thus the functional verbs like make which schematize the result are the least constrained, the verbs that imply some change less constrained and the verbs that do not imply any change the most constrained cross-linguistically. So the integrated constructional approach gives a better explanation of the cross-linguistic variations of the V-R constructions. Second, the bottom-up approach presupposes a set of underlying syntactic-semantic categories and this problem also exists in the formalist and other functionalist theories. Croft (2001) had fiercely attacked the universal syntactic 
categories and argued that there is no primitive syntactic or semantic category which can only be defined in the constructions. The V-R constructions are varied in and across languages and we have no idea what the finite inventory of primitive categories is. Moreover, unlike the formalist approach which prescribes the expressions by means of a set of syntactic-semantic categories, the integrated constructional approach does not give the absolute predication, but finds out the motivation of the variations. In short, the integrated constructional approach accounts for cross-linguistic variations of the V-R constructions which in return provide evidence for the constructional approach.

\section{Conclusions}

This paper attempts to make a detailed analysis of the V-R constructions in the constructional approach and proposes a more integrated constructional approach. While in Goldberg's analysis, the added argument role of the verb like sneeze in the caused-motion construction is fully assigned by the whole construction, the more integrated constructional approach suggests that the unconventional use of the verb is simultaneously categorized by the conventional verb and the construction. Besides, the integrated constructional approach further argues that the relationship between components and the construction can be regarded as the relationship between parts and the whole. A well-formed expression not only requires compatibility between the components and the construction but also compatibility among the components. For instance, in the V-R constructions, the verb and the result should be compatible in that the act designated by the verb can bring about the designated result. In this paper, the author does not elaborate on the importance of context to the expressions but the author hopes the readers should realize it. As Taylor (2002, p. 104) pointed out, the context is a factor in the interpretation of any utterance. And both Cognitive Grammar and Construction Grammar hold that there's no need to make a split between semantic meaning and pragmatic meaning. In some cases, the grammaticality of the V-R constructions in which the verb has not apparent relation with the result indeed can be enhanced in proper context which strengthens the relation between verb and the result. This paper also examines typological analysis of V-R constructions and provides explanations to the variations from the integrated constructional approach. To conclude, this paper elaborates on a more integrated approach to V-R constructions, which the author believes is instructive and will shed light on the analysis of V-R constructions and even other constructions.

\section{References}

Beck, S., \& Snyder, W. (2001). Complex predicates and goal PP’s: Evidence for a semantic parameter. A. H.-J. Do, L. Domínguez, \& A. Johansen (Eds.). Proceedings of the 25th Annual Boston University Conference on Language Development, 1, 114-122. Chomsky, N. (1981). Lectures on government and binding. Dordrecht: Foris.

Croft, W. (2001). Radical construction grammar: Syntactic theory in typological perspective. Oxford: Oxford University Press. Croft, W., \& Cruse, D. A. (2004). Cognitive linguistics (Cambridge textbooks linguistics). Cambridge: Cambridge University Press. Goldberg, A. E. (1995). Constructions: A construction grammar approach to argument structure. Chicago: University of Chicago Press.

Langacker, R. W. (2005). Construction grammars: Cognitive, radical, and less so. In F. J. R. de Mendoza Ibáñez \& M. S. P. Cervel (Eds.), Cognitive linguistics: Internal dynamics and interdisciplinary interaction. Cognitive Linguistics Research, 32, 101-159.

Langacker, R. W. (2008). Cognitive grammar: A basic introduction. New York: Oxford University Press.

Lemmens, M. (2006). More on objectless transitives and ergativization patterns in English. Constructions, 1-6, 1-37. Retrieved from www.constructions-online.de 
Levin, B. (2004). Verbs and constructions: Where next?. Retrieved from http://www.stanford.edu/ bclevin/pubs.html

Levin, B. (2012). Manner and result: Implications for argument realization across languages. Retrieved from http://www.stanford.edu/ bclevin/pubs.html

Levin, B., \& Rappaport Hovav, M. (2001). An event structure account of English resultatives. Language, 77, 766-797.

Levin, B., \& Rappaport Hovav, M. (2011). Manner and result as grammatically relevant ontological categories, handout for conceptual categories and linguistic categories. LSA Linguistic Institute, University of Colorado, Boulder, C.O..

Levin, B., \& Rappaport Hovav, M. (2012). Manner and result: Implications for argument realization across languages. Düsseldorf, Germany: Heinrich-Heine Universität. Retrieved from http://www.stanford.edu/ bclevin/pubs.html

Rappaport Hovav, M., \& Levin, B. (1995). Unaccusativity: At the syntax-lexical semantics interface. Cambridge, M.A.: MIT Press.

Rappaport Hovav, M., \& Levin, B. (1998). Building verb meanings. In M. Butt \& W. Geuder (Eds.), The projection of arguments (pp. 97-134). Stanford, C.A.: CSLI Publications.

Rappaport Hovav, M., \& Levin, B. (1999). Two structures for compositionally derived events. SALT, 9, 199-223.

Rappaport Hovav, M., \& Levin, B. (2010). Reflections on manner/result complementarity. In M. Rappaport Hovav, E. Doron, \& I. Sichel (Eds.), Syntax, lexical semantics, and event structure (pp. 21-38). Oxford, UK: Oxford University Press.

Rice, S. (1988). Unlikely lexical entries. Proceedings of the Fourteenth Annual Meeting of the Berkeley Linguistics Society, 14, 202-212.

Simpson, J. (1983). Resultatives. In L. Levin, M. Rappaport, \& A. Zaenen (Eds.), Papers in lexical-functional grammar (pp. 143-157). Bloomington: Indiana University Linguistics Club.

Snyder, W. (2001). On the nature of syntactic variation: Evidence from complex predicates and complex word-formation. Language, 77, 324-342.

Son, M., \& Peter, S. (2008). Microparameters of cross-linguistic variation: Directed motion and resultatives. In N. Abner \& J. Bishop (Eds.), Proceedings of the 27th west coast conference on formal linguistics (pp. 388-396). Somerville, M.A.: Cascadilla Proceedings Project.

Taylor, J. R. (2002). Cognitive grammar (Oxford textbooks in linguistics). Oxford: Oxford University Press.

Washio, R. (1997). Resultatives, compositionality and language variation. Journal of East Asian Linguistics, 6, 1-49.

ZHANG, R. (2006). Symbolic flexibility and argument structure variations. Linguistics, 4, 689-720. 